\title{
INTERVIEW
}

\section{Conversation Analysis for Second Language Acquisition and beyond: An interview with Numa P. Markee}

\author{
Natalia Evnitskaya \\ Universitat Autònoma de Barcelona, Barcelona, Spain
}

(Text received 16 July 2012; final version received 12 August 2012)

\begin{abstract}
Professor Numa P. Markee is Associate Professor of Linguistics at the University of Illinois at Urbana-Champaign (United States) where he teaches courses in Conversation Analysis, Second Language Acquisition, Task Based Language Teaching and in Language Program Administration. His principal research interests are in the area of ethnomethodological Conversation Analysis applied to Second Language Acquisition (CA-for-SLA), Discursive Psychology, socially distributed cognition, classroom research, the uses of technology in applied linguistics research and ESL teaching, and the management of curricular innovation. In addition to numerous journal articles and book chapters on CA-for-SLA - the main topic of the present interview Prof. Markee has also published a book Conversation Analysis (2000). The interview took place in January 2012 on the occasion of a series of conferences and workshops on Conversation Analysis carried out by Prof. Markee at the Universitat Autònoma de Barcelona (Spain) within the MA programme in Research on Language and Literature Education and as guest of the research group GREIP ${ }^{1}$.
\end{abstract}

INTERVIEWER: To start this interview, I would like to refer to your 2011 paper in which you discuss two different accounts of cognition. Could you tell us a few words about each one, please?

NUMA MARKEE: Okay, so the first one, which for want of a better way of describing it, we will call the traditional cognitive model of cognition, is something which is a very individual construct, that's to say, it's something that resides in the head of the individual. And the general idea in psychology and in psycholinguistics in particular is that there are underlying cognitive structures which generate in much the same sense as in generative grammar: the surface manifestations of cognition which is talk. In socially distributed cognition however, to use a technical phrase from Conversation Analysis (CA), you are ethnomethodologically indifferent to what psychology may or may not 
have said before and you look at how cognition and indeed other topics of psychology such as affect, learning, etc. are actually done as conversational topics. And so you do not assume that there is anything underlying conversation; conversation is the natural habitat in which cognition gets done.

INTERVIEWER: When you say that cognition is socially distributed in interaction you propose an analytic methodology which you call Language Learning Behaviour Tracking. How can it help us empirically find evidence that language learning actually takes place in interaction?

NUMA MARKEE: Well it has to be manifested in interaction, you have to be able to track whatever it is of the learning object that you are tracking, so whether it be an individual vocabulary item, or a piece of grammar, or a piece of sequential organization such as how, for example, one does compliment responses or gives advice or makes an invitation, etc. So you should be able to track these learning objects over hopefully an extended period of time and to see some demonstrable form of change which is appropriated by usually one individual - but may be appropriated by several - and which is maintained over preferably a long period of time. And so you have to see this behaviour actually occurring, some form of change in that behaviour and some sort of maintenance of that behaviour over hopefully an extended period of time.

INTERVIEWER: When you are talking about 'tracking', what do you mean by 'tracking'? How can we track it in interaction? What are the indicators?

NUMA MARKEE: Let's say that you notice, for example, that a particular vocabulary item is problematic, that it is not apparent in the talk of one or more participants, that it is introduced into the talk, that it becomes appropriated in the talk, as I said, that it manifests itself over time, and you track all the instances that you have available in your recordings and transcripts. The obvious problem with this is that you may well have instances of when the learning object happens during conversations which you are not able to record. A concern, if you like, is that, how do you know that this is the complete database that is potentially available? And a short answer is that you don't. So, that's the best that I can do so far in terms of working on this methodology. 
INTERVIEWER: Yes, just trying to find all the instances in all moments possible.

NUMA MARKEE: Right, exactly. And not only within talk but, for example, let's say that you have a unit of work, materials which last a week or two weeks or whatever it is. And what I am particularly fascinated by is how the learning object manifests itself in talk, may reappear in written work, may reappear in other kinds such as Power Point, etc. and if you can track all that and see how the learning object changes over time, that's really interesting but that's really difficult to do.

INTERVIEWER: In relation to your last comment, I would like to ask you the following: you said that in order to track language learning behaviour you have to compare how students participate in interaction and how they show their learning in written production over a long period of time. So, my question is: is it possible to apply this methodology to longitudinal data when it can happen that learners use different strategies, in the sense that they don't just adapt or improve their strategy/ies but they rather use completely other type of strategies when they come to some other or higher level of competence?

NUMA MARKEE: Well, the first thing that I would note is that I myself do not use the word 'strategies'. You will find that the concept is being used in CA literature; the reason why I do not talk about strategies is because from my perspective specifically within the Second Language Acquisition (SLA) literature it carries with it a lot of psycholinguistic baggage and so I want to be ethnomethodologically indifferent to all that kind of stuff. So I would prefer to talk about perhaps 'conversational practices'. If you can see that there are associated sets of conversational practices which are related conceptually or in terms of the kinds of things that they try to achieve in and through the talk, then that is an even richer analysis than the one I have been proposing up till now and undoubtedly will be even more difficult to do. So, it's an interesting idea but I don't think it's been done so far.

INTERVIEWER: Yeah, there's actually a broad discussion on this topic, whether CAfor-SLA methodology can be applied for longitudinal studies. 
NUMA MARKEE: Right. So, I think that, can CA be applied to this kind of stuff? Yes, absolutely. We're very much at the beginning of trying to work out how these things can be achieved and if you look at the kinds of things that different people have done everybody has a different way of doing it. So, for example, Richard Young and his students attempt to just try and find the same kinds of things being recycled over a period of time without it having been necessary to show that, let's say, you've got four weeks worth of work and the end result is different from what you get at the beginning. Not having to show that people are orienting to what has previously happened in order for this to work. That's what I want to be able to do, in other words, I want to be able to show that there's been studying of the object over time and that people are observably orienting to each previous occurrence each time they do occurrence. So it's a much stricter approach to doing longitudinal stuff than what some of my friends and colleagues have been doing. But that's not to say that it's not worth doing it. As I've said, longitudinal stuff is in its infancy in CA and so the more people actually work on this, the better we will know how to do it, I think. But even just where we stand now, it's about three, four, five of us who have done some work on this, you'll find that each one of us does slightly different things and for different reasons.

INTERVIEWER: Ok, this links to my next question. Since we already moved to a broader CA context, in your conference at the Universitat Autònoma de Barcelona you briefly mentioned research done in the field of Discursive Psychology (DP). So, what is, in your opinion, the relationship between Conversation Analysis and Discursive Psychology?

NUMA MARKEE: Well, they are both spin offs, so the mother discipline is Ethnomethodology (EM). Conversation Analysis is concerned with only conversation and by extension with institutional talk and it is concerned with how people achieve courses of action in and through talk from the participants' perspective. Discursive Psychology started out as a form of Discourse Analysis in the 1980s, I guess, or early 1990s and it was not limited just to talk but also to written materials, that why Discursive Psychology is interesting to me among other things. More recently, that's to say, the late 1990s onwards, the predominant methodological tool that Discursive 
Psychology has been using is CA. But it does so in order to talk about topics that are normally thought of as being things that psychologists say they are interested in such as cognition, affect, stance, etc. So, these are things that have been traditionally worked on from a very individual cognitivist perspective. And so, what discursive psychologists have been doing is to re-specify those kinds of things that psychologists are interested in as things that they actually do and achieve in and through talk. And so, that's again a very different perspective and an important re-specification of what has been a predominantly cognitive field.

INTERVIEWER: Are there any possible advantages of CA when compared to DP? Or how can both of them contribute to language learning research?

NUMA MARKEE: CA-types and DP-types are on the same epistemological side, but you will find that each side engages in polemics with the other on why their particular way of doing something is superior to the other and so, it's not as if they are completely in the same bed. I mean that there are distinct differences. From the perspective of SLA, it seems to me that the reason why DP is interesting is because it explicitly looks at psychological topics, which may be a way of...

INTERVIEWER: Complementing?

NUMA MARKEE: Oh, yeah, yeah, certainly. So, basically I think that CA and DP are different, there are arguments between the two disciplines; there are tensions. People who want to use these two disciplines for the purpose of looking at SLA should be aware of these tensions. I think that we should embrace those tensions so that we can see which particular perspective is most enlightening on a case-by-case basis to look at whatever data we are looking at. And to the extent that DP engages specifically with psychological topics, that is something which may be of particular interest to people interested in SLA. And so that's why I like what DP does a lot. But again I mean there are two, three people that I know of who do this: Gabi Kasper... Gabi and I often come to the same conclusions independently about the same time about the worth of something. So, for example, I guess we jointly coined the term CA-for-SLA and the 2004 MLJ special issue which I guest edited that's where the term was kind of..., we 
both used it and it was the beginning in that sense. I guess both of us were using that term independently and we found out about this. I actually think that we have to get rid of this term, CA-for-SLA, because if we are really explicitly bringing stuff from Ethnomethodology and from Discursive Psychology and Conversation Analysis, then we no longer talk about just CA-for-SLA. Mi-Suk Seo and I did a paper [2009] for a special issue that I co-edited with Junko Mori on socially-distributed cognition [2009] and in this paper we floated the term 'Learning Talk Analysis' (LTA) but that hasn't been really picked up...

INTERVIEWER: Which one?

NUMA MARKEE: Learning Talk Analysis? If you think of it, it is a supra-order term where we got kind of four bases: you got stuff from Wittgenstein, you got EM and Garfinkel, Schutz, etc., you also got CA and then you got DP and may be you will need to do interactional linguistics as well. So, these were kinds of interconnected ethnomethodological disciplines which together add up to much more than CA and we tried to call it 'Learning Talk Analysis'. But the term doesn't seem to have got much traction. I think I'll have another go with it trying to specify what LTA might be and why it might be beneficial to have this term as a potential replacement for CA-for-SLA.

INTERVIEWER: And why did you call it Learning Talk Analysis? If you say that learning and cognition are socially distributed activities, it means teacher and learner, then perhaps it should be 'teacher and learner talk analysis'.

NUMA MARKEE: Well, what I was trying to do is to sketch out the parameters of a very specific niche of the kind of work that I want to do myself and which I think other people should do. So it's not 'learning' and then 'talk analysis', it's 'learning talk'. Talk in which you do language learning behaviour. This is a very specific kind of talk, specifically institutional. So I wanted that term to be something which is very specific to a particular kind of work which has up till now been called CA-for-SLA.

INTERVIEWER: It looks like a promising term. 
NUMA MARKEE: Yeah, sure.

INTERVIEWER: I would like to turn now to my last question. Considering that we are not only language teachers but also teacher educators, do you think it is a feasible task to create practical guides for language teachers on how to use CA methodology or LTA methodology in order to reflect on their teaching practices through the analysis of their classrooms and to get conclusions that could allow them improve their classroom practices?

NUMA MARKEE: Oh, absolutely. What I often did in my classes was a demonstration for students, specifically students who are training to be applied linguists including people who are specifically interested in being language teachers, of how CA works in terms of recording, transcription, etc. And then basically what I did was to reverse engineer the analysis, that's to say, I thought: What steps did I go through in terms of doing original research? What were the things that I had to work out? So I came out with a bunch of six or seven questions which reconstruct for the students my own analytic steps and then I got them to do the analysis using those questions as guidelines. I think it is very valuable for students. If what you want to do is to be a language teacher I think it is imperative at some stage in your master's training to have the opportunity to record preferably your own classroom and you doing your stuff in that classroom. And then transcribing all that stuff and being able to see first of all what people are actually doing as opposed to perhaps what you wanted them to do - because those things are always different - and certainly to see what people actually do as opposed to what they should be doing. And that, I think, is a potentially and immensely valuable source of insight into what you did as a teacher. And certainly I have found that to be very valuable in terms of my own language teaching and applied linguistics teaching as it helps me to see how my materials were working or not, as the case may be, and how I actually talk that stuff through and, for example, the difference between the written instructions which I have in the materials and then how I do those instructions in order to explain them to the students. So, I think teachers should have at least one opportunity in their lives to be able to look at that. I think it's crucial.

INTERVIEWER: So, the conclusion is that we should encourage our secondary or 
primary or university teachers to use video recordings and CA methodology?

NUMA MARKEE: Well, with video recordings they may not have the time, the inclination or the kind of practice that is necessary to do a full-blown strict CA but nonetheless they should be able to do fieldwork that would integrate these kinds of materials. But I think if they want to be teachers, which is a very important and very honourable profession, well, I don't want to say that all should be researchers, but rather being able to see what you are actually doing in classes and obtain this experience is important. So, yes, video is wonderful for that.

INTERVIEWER: Yeah, but then that was my question -how to show or teach CA methodologies to teachers who are not used to doing research?

NUMA MARKEE: Well, I think that basically you do the original research yourself and then preferably use a website so that you can integrate the written materials with transcripts, the audio and video files, etc. You do a set of questions which mirror the research process that you went through and these questions lead the students to essentially do a CA analysis. But in terms that are manageable, that is, that they don't have to know the terminology but they get really pretty deep insights into what's going on and so they are doing a CA analysis on their own. I think a guided approach to doing the research is the way to go because you can't just throw people into the deep end and expect them to do CA. So, you have to do a lot of the work beforehand so that first of all it's got to be accessible to students. So that you are pretty sure that they're going to be successful in terms of doing the analysis and coming to conclusions that are supportable in terms of the data. In this way you don't have to wait for two or three years until they are competent CA analysts in order for them to do this. I do this with my own students who have never done CA before and I don't tell them necessarily, 'This is CA', I tell them, 'This is what goes on in the classroom'. But I think that's crucial, I mean in terms of my own work as a language educator I use that kind of stuff a lot and usually the students respond very well to that.

INTERVIEWER: Thank you very much for your time and all your invaluable insights into the language learning behaviour tracking, CA methodology and learning talk 
analysis. I'm eager to see how the latter works.

NUMA MARKEE: Well, so am I! May be it doesn’t who knows, but we'll see.

\title{
References:
}

Markee, N.P.P. (2000). Conversation Analysis. Mahwah, N.J.: Lawrence Erlbaum.

Markee, N.P.P. (ed.) (2004). Classroom Talks. Special Issue of Modern Language Journal, 88/4: 491-616.

Markee, N.P.P., \& Seo, M.-S. (2009). Learning talk analysis. International Review of Applied Linguistics in Language Teaching, 47/1: 37-63.

Mori, J., \& Markee, N.P.P. (eds.) (2009). Language learning, cognition, and interactional practices. Special Issue of International Review of Applied Linguistics in Language Teaching, 47/1: 1-156.

Markee, N.P.P. (ed.) (2011). Doing, and justifying doing, avoidance. Journal of Pragmatics, 43/2: 602-615.

\footnotetext{
${ }^{1}$ Grup de Recerca en Ensenyament i Interacció Plurilingües, Universitat Autònoma de Barcelona, Spain (greip.uab.cat)
}

\begin{abstract}
Author References:
Natalia Evnitskaya works as a teacher educator and a junior researcher at the Department of Language and Literature Education, Universitat Autònoma de Barcelona (Spain). She is a member of the Research Group on Plurilingual Interaction and Teaching (GREIP) and of the Action-Research Collaborative Team CLIL-SI which runs school-university partnership projects for the promotion of plurilingual education in inclusive classrooms. She has participated in several research projects on CLIL funded by the Spanish and Catalan governments and published various papers on the topic. Her main research interests are Content and Language Integrated Learning (CLIL), classroom interaction, foreign language teaching and learning, innovative approach to teacher education, Conversation Analysis, Multimodal Analysis.
\end{abstract}

Email: Natalia.Evnitskaya@uab.cat

To cite this article:

Evnitskaya, N. (2012) Conversation Analysis for Second Language Acquisition and beyond: An interview with Numa P. Markee. Bellaterra Journal of Teaching \& Learning Language \& Literature, 5(3), 57-65. 